\title{
REVIEWS
}

\section{Efficacy and Safety of Tunneled Pleural Catheters in Adults with Malignant Pleural Effusions: A Systematic Review}

\author{
Margaret E. M. Van Meter, $M D^{7}$, Kanako Y. McKee, $M D^{2}$, and R. Jeffrey Kohlwes, MD, MPH ${ }^{2,3}$ \\ 'Division of Cancer Medicine, The University of Texas MD Anderson Cancer Center, Houston, TX, USA; ${ }^{2}$ Department of Medicine, The University \\ of California, San Francisco, San Francisco, CA, USA; ${ }^{3}$ PRIME Residency Program, Veterans Affairs Hospital, San Francisco, CA, USA.
}

BACKGROUND: Malignant pleural effusions (MPE) are a frequent cause of dyspnea and discomfort at the end of cancer patients' lives. The tunneled indwelling pleural catheter (TIPC) was approved by the FDA in 1997 and has been investigated as a treatment for MPE.

OBJECTIVE: To systematically review published data on the efficacy and safety of the TIPC for treatment of MPE. DESIGN: We searched the MEDLINE, EMBASE, and ISI Web of Science databases to identify studies published through October 2009 that reported outcomes in adult patients with MPE treated with a TIPC. Data were aggregated using summary statistics when outcomes were described in the same way among multiple primary studies. MAIN MEASURES: Symptomatic improvement and complications associated with use of the TIPC.

KEY RESULTS: Nineteen studies with a total of 1,370 patients met criteria for inclusion in the review. Only one randomized study directly compared the TIPC with the current gold standard treatment, pleurodesis. All other studies were case series. Symptomatic improvement was reported in 628/657 patients (95.6\%). Quality of life measurements were infrequently reported. Spontaneous pleurodesis occurred in 430/943 patients (45.6\%). Serious complications were rare and included empyema in $33 / 1168$ patients $(2.8 \%)$, pneumothorax requiring a chest tube in $3 / 51$ (5.9\%), and unspecified pneumothorax in 17/439 (3.9\%). Minor complications included cellulitis in 32/935 (3.4\%), obstruction/clogging in 33/ $895(3.7 \%)$ and unspecified malfunction of the catheter in $11 / 121(9.1 \%)$. The use of the TIPC was without complication in 517/591 patients (87.5\%).

CONCLUSIONS: Based on low-quality evidence in the form of case series, the TIPC may improve symptoms for patients with MPE and does not appear to be associated with major complications. Prospective randomized studies comparing the TIPC to pleurodesis are needed before the TIPC can be definitively recommended as a first-line treatment of MPE.

KEY WORDS: malignant pleural effusion; tunneled catheter; palliative care.

J Gen Intern Med 26(1):70-6

DOI: $10.1007 / \mathrm{s} 11606-010-1472-0$

(C) The Author(s) 2010. This article is published with open access at Springerlink.com

Received February 16, 2010

Revised June 29, 2010

Accepted July 12, 2010

Published online August 10, 2010

\section{CASE PRESENTATION}

A 68-year-old retired coal miner with widely metastatic lung cancer reports shortness of breath and constant dull chest pain. A chest radiograph demonstrates a recurrent massive pleural effusion that was previously treated with therapeutic thoracentesis with symptomatic relief. He expresses a desire for symptom control measures that would allow him to attend his granddaughter's college graduation, as she is the first person in his family to graduate. He is at high risk for general anesthesia due to severe emphysema. How effective is an indwelling pleural catheter as a palliative option for management of his pleural effusion?

\section{INTRODUCTION}

Malignant pleural effusions (MPE) occur in up to $15 \%$ of patients with advanced malignancies and contribute significantly to dyspnea and discomfort at the end of cancer patients' lives. ${ }^{1}$ The current standard of care for MPEs that reaccumulate after percutaneous drainage is pleurodesis. Pleurodesis, using chemical and physical agents, has been the mainstay of treatment for decades, but questions have been raised about its safety. Talc, the most effective and commonly used pleurodesis agent, has been shown to have multiple complications, including respiratory failure, pneumonia, and treatment-related death. ${ }^{2,3}$ There is evidence that these serious risks are reduced through the use of more carefully regulated talc particles. ${ }^{4}$ However, pleurodesis is also associated with fever, pain, and often necessitates general anesthesia and a several-day hospitalization.

Since its approval by the FDA in 1997, the tunneled indwelling pleural catheter (TIPC) has increasingly been used as an alternate therapy. The indwelling catheter is inserted percutaneously and allows for intermittent drainage at home through an easily managed tube. ${ }^{5}$ Shortly after FDA approval, Putnam and colleagues published the only randomized trial to date comparing pleurodesis to TIPC for MPE. ${ }^{6}$ They found that TIPC patients experienced fewer in-hospital complications and a similar improvement in quality of life when compared with pleurodesis, but a lower rate of spontaneous pleurodesis and higher rates of late complications. Since Putnam's publication, the use of these drainage systems has become more widespread, and multiple large and small observational studies using the TIPC to treat MPE have been published.

The goal of our study is to locate, evaluate, and summarize existing clinical studies examining the safety and efficacy of the TIPC for MPE in order to help clinicians understand the risks and benefits of using these devices. We also hope to provide a foundation to encourage future randomized studies directly 
comparing pleurodesis to TIPC. To accomplish this, we conducted a systematic review of published studies to explore the efficacy and safety of tunneled indwelling pleural catheters in the treatment of MPE.

\section{METHODS}

\section{Data Sources and Searches}

We searched the MEDLINE, EMBASE, and ISI Web of Science databases for all relevant articles published through October 2009. The search strategy was created together with a research librarian and designed to capture all terms that may be used describe malignant pleural effusions and pleural catheters. Complete search terms for each database are included in Table 1. We also manually searched the reference lists of included studies and relevant reviews for additional studies not detected by the electronic literature searches.

\section{Study Selection}

Studies with and without a control group were eligible if they included at least eight consecutive adult patients with an effusion in the setting of malignancy who received an indwelling, tunneled pleural catheter. Criteria for exclusion were studies of nonmalignant effusions, empyema, or chylothorax; studies of large bore chest tubes or non-tunneled catheters; studies in which all patients underwent thoracoscopy, video-assisted thoracoscopic surgery (VATS), or pleurodesis; studies not published in the English language; and studies without primary data. If data appeared to be duplicated in multiple publications, only the study with the most complete data set was included, and studies excluded for this reason are explicitly noted. If a study was otherwise eligible but contained an identifiable subset of patients with excluded types of effusions or surgical procedures, the study was included and analyzed for the subset of interest.

\section{Data Abstraction and Quality Assessment}

Data were abstracted independently by two authors (MVM, KYM); discrepancies were resolved by discussion and consul-

\section{Table 1. Search Strategy Used to Identify Studies Describing the Use of Tunneled Indwelling Pleural Catheters in the Treatment of Malignant Pleural Effusions}

\begin{tabular}{ll}
\hline \hline MEDLINE & [(Malignant pleural effusion OR malignant \\
& pleural effusions) OR (pleural effusion[MH] \\
& AND (neoplasms[MH] OR malignant[TIAB])] \\
& AND (indwelling catheters OR indwelling catheter \\
& OR catheterization[MH:noexp] OR catheter* \\
& OR chest tube OR chest tubes OR "pleural tube" \\
& OR "pleural tubes") \\
Web of Science & Topic = [(malignant same pleural effusion*) \\
& OR (malignant same pleura effusion*)] AND \\
& topic = (indwelling OR catheter* OR chest tube* \\
& OR pleural tube*) \\
EMBASE & ("Indwelling catheter"/exp OR "catheters and tubes"/ \\
& de OR "catheter"/de OR "tube"/de OR "drain"/de) \\
& AND (("pleura effusion"/de AND "malignant") OR \\
& ("pleural effusion":ti,ab OR "pleura effusion":ti,ab \\
& AND "malignant":ti,ab)) \\
\hline
\end{tabular}

tation with the third author (RJK). Abstractors were not blinded to any details regarding the included studies. From each study, data were abstracted on participant age, sex, cancer type, prior treatments for effusion, length of time catheter was in place, amount of fluid drained, occurrence of spontaneous pleurodesis, symptomatic relief, quality of life, complications, hospital days, and survival days. For every outcome described in a particular study, the authors determined the numerator (i.e., the number of subjects that experienced that outcome) and denominator (i.e., the number of total subjects). Very few studies reported data on all outcomes of interest; if an outcome was not reported, that study was not included in either the numerator or the denominator. If more than one interpretation of outcomes data was possible, such as due to a discrepancy within a paper, the authors of the primary study were contacted for clarification. If the authors could not be reached, the abstractors opted towards the interpretation that would not bias in favor of the TIPC. The quality of evidence presented in the primary studies was evaluated using the Grading of Recommendations Assessment, Development, and Evaluation (GRADE) Working Group system. ${ }^{7}$

\section{Data Synthesis and Analysis}

In review of the studies, patient populations and interventions were felt to be relatively homogeneous, as described further in the Results. There was, however, significant variation in outcome reporting. Outcomes that were described in a similar way among multiple primary studies were aggregated by summing the numerator and denominator for each given outcome to yield the total number of events per total number of subjects. Outcomes that were not the same or were not described in the same way (such as "obstructed catheter" and "malfunction of catheter") were not combined. For outcomes that were combined, means were calculated using summary statistics. To give readers a measure of the uncertainty around the calculated mean values, we included the range of values reported in the primary studies. The overall mean was calculated for patient survival and catheter permanence time from studies that reported this information. All analyses were performed using Microsoft Office Access and Excel 2007.

\section{RESULTS}

As detailed in Figure 1, the literature search identified 1,011 potentially eligible reports. After review of the title, abstract, or complete manuscript, 986 reports were excluded based on the inclusion and exclusion criteria. Only two studies ${ }^{8,9}$ that appeared to meet other criteria were excluded due to nonEnglish language; the authors of one of these ${ }^{8}$ later published their experience in English, and this study is included. ${ }^{10}$ Of the remaining 25 eligible reports, 6 were excluded due to overlap with patients reported in other studies. ${ }^{11-16}$

The 19 included reports (Table 2) were all consecutive case series of patients with MPE who received a TIPC, except one randomized controlled trial of doxycycline pleurodesis versus TIPC; only the group receiving the TIPC is included in this analysis. ${ }^{6}$ Three meeting abstracts ${ }^{10,17,18}$ and one letter ${ }^{19}$ were eligible and presented sufficient data to be included in the 


\begin{tabular}{|c|c|c|c|c|}
\hline \multicolumn{2}{|c|}{ Potentially eligible reports $(n=1011$ ) } & $\begin{array}{c}\text { MEDLINE } \\
440\end{array}$ & $\begin{array}{c}\text { WoS } \\
425\end{array}$ & $\begin{array}{c}\text { EMBASE } \\
146\end{array}$ \\
\hline \multicolumn{5}{|c|}{ Reports excluded $(n=986)$} \\
\hline & Duplicated across databases & - & 169 & 118 \\
\hline & Not tunneled pleural catheter & 174 & 164 & 6 \\
\hline & Not malignant pleural effusion & 61 & 23 & 1 \\
\hline & Pleurodesis & 95 & 30 & 11 \\
\hline & Thoracoscopy or VATS & 22 & 9 & 2 \\
\hline & Included $<8$ patients & 12 & 1 & 1 \\
\hline & Review / no primary data & 44 & 18 & 6 \\
\hline & Insufficient data reporting & - & 6 & - \\
\hline & Non-English language & 2 & - & - \\
\hline & Pediatric patients & 9 & - & - \\
\hline & Animal model & 2 & - & - \\
\hline \multicolumn{2}{|c|}{ Eligible reports $(n=25)$} & 19 & 5 & 1 \\
\hline & Eligible reports excluded $(n=6)$ & & & \\
\hline & Patient overlap & 3 & 2 & 1 \\
\hline \multicolumn{2}{|c|}{ Included reports $(n=19)$} & 16 & 3 & 0 \\
\hline
\end{tabular}

Figure 1. Article selection process. Abbreviations: WoS, Web of Science; VATS, video-assisted thoracoscopic surgery

analysis. Eight studies were conducted outside the USA. All except one study ${ }^{20}$ employed the Pleurx ${ }^{\circledR}$ tunneled pleural catheter system initially manufactured by Denver Biomedical (Golden, Colorado), a company that was acquired by Cardinal Health (Dublin, Ohio) in 2006. The oldest study, published in 1994, used a tube known as the Tenckhoff catheter, which is also a small-bore flexible catheter that was tunneled into the pleural space. ${ }^{20}$ One study employed a reusable plastic pump to drain pleural fluid instead of the standard vacuum drainage bottles designed for use with the Pleurx ${ }^{\circledR}$ catheter. ${ }^{21}$ Funding source was noted for only two reports, and in those cases the study was supported by the Pleurx® manufacturer. ${ }^{\circledR, 22}$ Quality of evidence, as rated using the GRADE system, was very low for all of the case series and moderate for the one randomized controlled trial. ${ }^{6}$

A total of 1,370 patients were included in the analysis, with an average age of 63.0 years and $50.5 \%$ women. Of the 1,370 patients, 1,348 patients had malignant pleural effusions; two studies included a minority of patients with pleural effusions of benign etiology, such as heart failure and hepatic hydrothorax. ${ }^{23,24}$ Because data were not reported separately for the patients with non-MPE, these 22 patients were included in the overall analysis, but are felt to contribute insignificantly. Most patients had recurrent effusions that had failed previous thoracentesis or other treatments; details of the individual patient populations are included in Table 2 . In the 17 studies that reported distribution of cancer type among 1,236 participants, lung cancer, breast cancer, and mesothelioma together comprised approximately $70 \%$ of the included patients $(33.5 \%, 25.9 \%$, and $10.5 \%$, respectively). A variety of other hematologic malignancies and solid tumors were represented in smaller numbers, as described in Table 2.

Survival and catheter permanence times were reported in 10 and 11 studies, respectively, either as a median or a mean, with or without a range. These times were defined starting from the day of TIPC placement. Survival varied from 3 to 1,240 days, with a combined mean of 87 and reported medians ranging from 59.5 to 144 days. Catheter permanence time varied from 2 to 434 days, with a combined mean of 51 and reported medians ranging from 44 to 60 days.

Studies differed significantly in how they reported outcomes, but results were pooled when possible, as described in the Methods section. Combined outcomes are presented in Figure 2. Note that denominators in this figure are different because not all studies reported all complications, and if an outcome was not recorded, the study was removed from both the numerator and denominator.

Of the reported complications, malfunction of the catheter $(11 / 121,9.1 \%)$, catheter clogging $(33 / 895,3.7 \%)$, and unspecified pain $(8 / 142,5.6 \%)$ were the most common. One study reported that mild procedure-related pain occurred in "most" patients, ${ }^{23}$ but pain that persisted beyond the immediate postprocedural period was documented formally in only 18/558 patients (3.2\%) from five studies. Infectious complications such as empyema $(33 / 1168,2.8 \%)$, cellulitis $(32 / 935,3.4 \%)$, and unspecified infection $(7 / 346,2.0 \%)$ were similarly uncommon. The TIPC was removed before death because of a complication in $54 / 633$ patients $(8.5 \%)$. Tumor metastasis along the catheter tract, although initially a strong theoretical concern, was well documented in these studies and occurred in less than $1 \%$ of patients. One procedure-related death was reported in the earliest published study and was related to respiratory arrest following intravenous sedation in a patient who had previously requested no resuscitation. ${ }^{20}$ Ten studies reported that TIPC devices were used without any complication in a total of 517/591 patients $(87.5 \%)$.

Symptomatic improvement was reported in a variety of ways. Some studies simply stated that patients experienced "symptomatic improvement" without further delineation. ${ }^{10,20,25}$ One study rated dyspnea improvement on a 3-point scale as complete, partial, or absent. ${ }^{26}$ The remaining studies reported symptomatic improvement as "relief of dyspnea," "improvement in respiratory performance status," "increased exercise tolerance," "improvement of pain," and "catheter was useful." In sum, these studies showed that $95.6 \%$ of patients experienced symptomatic improvement after placement of the TIPC. Putnam et al. ${ }^{6}$ used Borg scores and the Guyatt Chronic Respiratory Questionnaire to assess symptomatic improvement and found similar improvements after treatment with both the TIPC and doxycycline pleurodesis; the number of patients with improvement was not reported and therefore could not be included in this combined outcome statistic. Quality of life assessments were infrequently included, but 46/46 patients from two studies cited improvement from the TIPC. ${ }^{27,28}$

Spontaneous pleurodesis was also defined in a variety of ways. In general, these studies used the term spontaneous pleurodesis to describe enduring or long-term achievement of pleural symphysis allowing for TIPC removal without recurrence of the pleural effusion, although some patients chose to keep the catheters in place despite achievement of pleurodesis. Spontaneous pleurodesis occurred in 430/943 patients, for an overall rate of $45.6 \%$, with an average time to pleurodesis of 52 days. The catheter was removed due to pleurodesis in $381 / 808$ patients (47.1\%). Recurrence of effusion after initial control was reported in $50 / 651$ patients $(7.7 \%)$, and $33 / 652$ patients $(5.1 \%)$ 
Table 2. Characteristics of the 19 Studies Included in the Systematic Review

\begin{tabular}{|c|c|c|c|}
\hline First author, year & n & Study setting and patient population* & Cancer types \\
\hline Al-Halfawy, ${ }^{21} 2008$ & 55 & $\begin{array}{l}\text { Academic center in Egypt. MPE not necessarily previously } \\
\text { treated with thoracentesis }\end{array}$ & $\begin{array}{l}\text { Lung } 21 \text {, breast } 16 \text {, mesothelioma } 10 \text {, } \\
\text { lymphoma } 2 \text {, colon } 3 \text {, other } 3\end{array}$ \\
\hline Bazerbashi, ${ }^{29} 2009$ & 125 & $\begin{array}{l}\text { Academic center in the UK. Patients with trapped lung } \dagger \text { found } \\
\text { during VATS, failed pleurodesis, or recurrent effusion. } 62 \% \text { of } \\
\text { TIPC inserted during VATS }\end{array}$ & Lung 33, breast 19 , mesothelioma 42 , other 31 \\
\hline Bertolaccini, ${ }^{10} 2009$ & 77 & $\begin{array}{l}\text { Unknown setting in Italy. Patients with at least } 1 \text { prior } \\
\text { thoracentesis }\end{array}$ & $\begin{array}{l}\text { Lung } 37 \text {, breast } 15 \text {, mesothelioma } 15 \text {, colon } 7 \text {, } \\
\text { pancreas } 2 \text {, ovarian } 1\end{array}$ \\
\hline Diez-Porres, ${ }^{19} 2008$ & 8 & $\begin{array}{l}\text { Palliative home care unit affiliated with public hospital in Spain. } \\
\text { Unknown prior treatment for MPE }\end{array}$ & $\begin{array}{l}\text { Lung } 3 \text {, breast } 1 \text {, mesothelioma } 1, \operatorname{RCC} 2 \text {, } \\
\text { other } 1\end{array}$ \\
\hline Mullett, ${ }^{17} 2003$ & 70 & $\begin{array}{l}\text { Academic center in the USA. Unknown prior MPE treatment. } \\
22 \% \text { inserted during concomitant surgical procedures }\end{array}$ & Lung 35 , breast 9 , hematologic 8 , other 18 \\
\hline Murthy, ${ }^{23} 2006$ & 58 & $\begin{array}{l}\text { Academic center in the USA. Patients with trapped lung } \dagger \text {, } \\
\text { high-volume effusions, or failed pleurodesis. } 22 \% \text { inserted } \\
\text { during planned thoracoscopy }\end{array}$ & $\begin{array}{l}\text { Lung } 22 \text {, lymphoma } 3 \text {, other } 23 \text {, } \\
\text { nonmalignant } 10\end{array}$ \\
\hline Musani, ${ }^{30} 2004$ & 24 & $\begin{array}{l}\text { Academic center in the USA. Patients with recurrent } \\
\text { free-flowing MPE }\end{array}$ & $\begin{array}{l}\text { Lung } 5 \text {, breast } 11 \text {, mesothelioma } 3 \text {, colon } 1 \text {, } \\
\text { RCC } 1 \text {, other } 3\end{array}$ \\
\hline Ohm, ${ }^{27} 2003$ & 34 & Academic center in the USA. Patients with trapped lung $\dagger$ & Cancer type distribution NS \\
\hline Pien, ${ }^{32} 2001$ & 11 & Academic center in the USA. Patients with trapped lung $\dagger$ & $\begin{array}{l}\text { Mesothelioma } 6 \text {, lymphoma } 3 \text {, multiple } \\
\text { myeloma } 1 \text {, other } 1\end{array}$ \\
\hline Pollak, ${ }^{31} 2001$ & 28 & $\begin{array}{l}\text { Academic center in the USA. Patients with recurrent MPE } \\
\text { after thoracentesis }\end{array}$ & $\begin{array}{l}\text { Lung } 10 \text {, breast } 3 \text {, lymphoma } 2 \text {, colon } 2 \text {, RCC } 2 \text {, } \\
\text { other } 9\end{array}$ \\
\hline Putnam, ${ }^{6} 1999$ & 99 & $\begin{array}{l}\text { Academic center in the USA. Patients with recurrent MPE } \\
\text { after thoracentesis }\end{array}$ & $\begin{array}{l}\text { Lung } 39 \text {, breast } 25 \text {, hematologic } 4, \operatorname{RCC~} 4 \text {, } \\
\text { other } 27\end{array}$ \\
\hline Putnam, ${ }^{22} 2000$ & 100 & $\begin{array}{l}\text { Academic center in the USA. Patients with at least } 1 \\
\text { prior thoracentesis }\end{array}$ & Distribution for TIPC cohort NS \\
\hline Robinson, ${ }^{20} 1994$ & 9 & $\begin{array}{l}\text { Academic center in the USA. Prior pleurodesis had failed } \\
\text { in } 4 \text { patients }\end{array}$ & $\begin{array}{l}\text { Lung } 3 \text {, breast } 2 \text {, lymphoma } 1 \text {, myeloma } 1 \text {, } \\
\text { RCC } 1 \text {, other } 1\end{array}$ \\
\hline Schneider, ${ }^{24} 2009$ & 100 & $\begin{array}{l}\text { Academic center in Germany. Patients had trapped lung } \dagger \text {, } \\
\text { previously failed pleurodesis, or were not VATS candidates } \\
\text { due to overall condition }\end{array}$ & $\begin{array}{l}\text { Lung } 23 \text {, breast } 20 \text {, mesothelioma } 11 \text {, } \\
\text { other } 34 \text {, nonmalignant } 12\end{array}$ \\
\hline Sioris, ${ }^{25} 2009$ & 51 & $\begin{array}{l}\text { Academic center in Finland. Patients with at least } 1 \text { prior } \\
\text { thoracentesis, rapid accumulation of fluid, trapped lungt, } \\
\text { or high surgical risk }\end{array}$ & $\begin{array}{l}\text { Lung } 21 \text {, breast } 7 \text {, mesothelioma } 7 \text {, lymphoma } 1 \text {, } \\
\text { RCC } 1 \text {, other } 14 \text {. All patients with trapped lung }\end{array}$ \\
\hline Tremblay, ${ }^{26} 2006$ & 223 & $\begin{array}{l}\text { Academic center in Canada. Patients with recurrent pleural } \\
\text { effusions. } 25 \% \text { had undergone prior unspecified pleural } \\
\text { intervention }\end{array}$ & $\begin{array}{l}\text { Lung } 92 \text {, breast } 49 \text {, mesothelioma } 29 \text {, } \\
\text { ovarian } 19 \text {, other } 61 \text {. (Distribution by } \\
\text { number of TIPC insertions) }\end{array}$ \\
\hline van den Toorn, ${ }^{28} 2005$ & 17 & $\begin{array}{l}\text { Academic center in the Netherlands. Patients with recurrent } \\
\text { effusions after thoracentesis and had failed or were } \\
\text { ineligible for pleurodesis }\end{array}$ & Lung 5 , breast 3 , mesothelioma 6 , other 3 \\
\hline Warren, ${ }^{33} 2008$ & 263 & $\begin{array}{l}\text { Academic center in the USA. Patients with MPE, most did not } \\
\text { have prior thoracentesis }\end{array}$ & Lung 60 , breast 133 ,gynecologic 32 , other 38 \\
\hline Wyckoff, ${ }^{18} 2003$ & 18 & Academic center in the USA. Patients with recurrent MPE & Lung 5 , breast 7 , lymphoma 1 , RCC 1 , other 4 \\
\hline
\end{tabular}

*TIPC inserted under local anesthesia unless otherwise noted

$\dagger$ Trapped lung is characterized by a thick, fibrous peel on the visceral pleura that prevents full reexpansion and pleural apposition after thoracentesis, leading to rapid reaccumulation of fluid and chronic pleural effusions

Abbreviations: MPE, malignant pleural effusion; NS, not specified; RCC, renal cell carcinoma; TIPC, tunneled indwelling pleural catheter; VATS, videoassisted thoracoscopic surgery

required repeat placement of the catheter after it had been removed.

\section{DISCUSSION}

The presence of a MPE portends a poor prognosis for cancer patients, with a median survival of 4.0 months; ${ }^{34}$ the American Joint Committee on Cancer (AJCC) staging system for lung cancer has recently been revised to reflect this. ${ }^{35}$ Given the limited life expectancy, treatment for MPE is often individualized to each patient's clinical characteristics and goals of care. While repeated therapeutic thoracentesis may provide sufficient symptomatic relief in some patients, others have a pleural effusion that is so large and rapidly accumulating that a more permanent intervention is required.

Due to his high operative risk, the patient with metastatic lung cancer described in the case presentation was not a good candidate for chemical or mechanical pleurodesis, the traditional standard of care for MPE. ${ }^{1,36}$ Data on the use of the TIPC for the treatment of MPE have been accumulating over the past 15 years. Prior reviews of the TIPC ${ }^{37-40}$ have included only a few select articles and focus on the data from the largest centers. To our knowledge, this report, which draws studies from multiple databases and includes a total of 1,370 patients, is the most rigorous and complete review published on this topic.

Although the results are limited by the low quality of the available evidence, as discussed below, our systematic review suggests that the TIPC may improve symptoms for patients with MPE and does not appear to be associated with major complications. Symptom relief was variably defined in the studies that reported it, and only 1 study $^{6}$ used validated scales; when combined, 628/657 patients (95.6\%) experienced some degree of improvement in their symptoms, although the magnitude of improvement cannot be determined. Spontaneous 


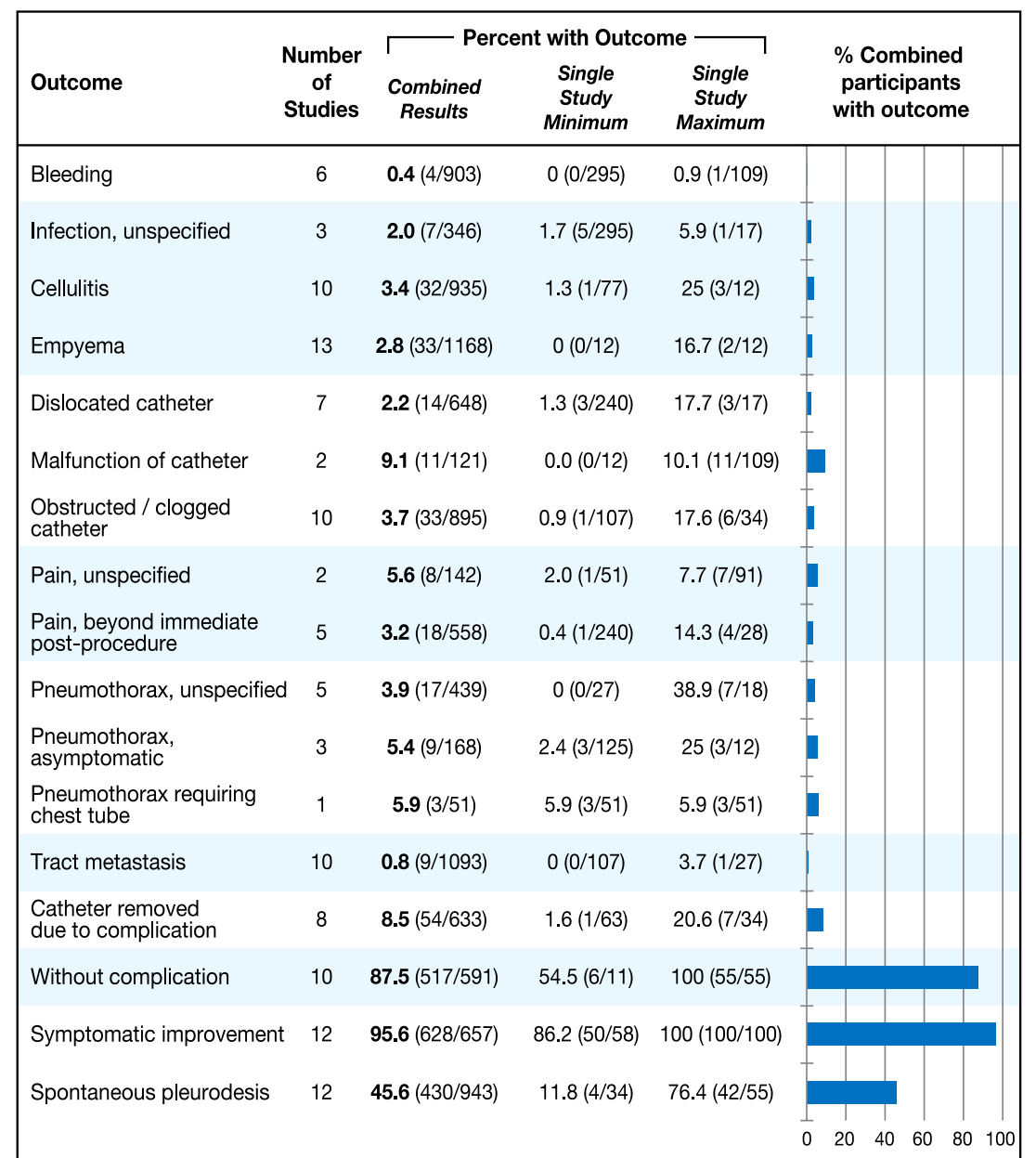

Figure 2. Outcomes reported in patients treated with the TIPC

pleurodesis occurred in $430 / 943$ (45.6\%); this is not the primary goal of TIPC placement, but does allow removal of the catheter and may contribute to symptom relief.

Complications of TIPC use were also not reported uniformly, and summary statistics could not be performed for each outcome. For combined outcomes that were described in the same way in the primary studies, we found that serious complications (those that may require an additional invasive procedure or hospital admission) were rare. Empyema was reported in 33/1168 patients (2.8\%) and unspecified infection in $7 / 346(2.0 \%)$. Pneumothorax requiring a chest tube was reported in 3/51 (5.9\%) and unspecified pneumothorax in $17 / 439$ (3.9\%). The most common minor complications were cellulitis $(32 / 935,3.4 \%)$, obstruction/clogging (33/895, $3.7 \%)$, or unspecified malfunction of the catheter $(11 / 121$, $9.1 \%)$. More catheters were removed due to achievement of spontaneous pleurodesis $(381 / 808,47.1 \%)$ than to complications (54/633, 8.5\%).

Interpretation and application of these results must be done with caution given the limitations of our study. Most importantly, the data come almost exclusively from uncontrolled, often retrospective, case series. In the widely used GRADE system, case series are categorized as very low quality evidence. ${ }^{7}$ These studies were not blinded, patients were not randomized to treatment, and outcomes were inconsistently reported. Even among the outcomes that were reported with some regularity, degree or severity was often not delineated. There is also potential for publication bias, especially at lessexperienced centers that have used the TIPC without as much success. Furthermore, although most of the largest studies in this review explicitly stated that they included consecutive patients who received the TIPC, 9 of the 19 studies did not state this, thus raising the possibility that some patients may have not been included in their series. Potential confounding factors, such as concurrent treatment with opioids or chemotherapy, were not reported. Finally, there is potential for bias in the way our systematic review was conducted. We attempted to minimize this by using a protocol for study inclusion and exclusion and by having two authors separately abstract the data.

While this study provides a suggestion that the TIPC may be useful in the treatment of patients with MPE, there is little evidence comparing the TIPC to traditional pleurodesis, and the patient population in which the TIPC could be best utilized remains undefined. For example, it is possible that patients with a longer survival may experience more TIPC complications due to longer catheter permanence time and would benefit instead from early mechanical or chemical pleurodesis. It is also unknown whether the TIPC may be more efficacious in effusions due to certain cancers. Warren et al. found that tumor type, the presence of malignant cells on pleural fluid cytology, and trapped lung are all predictive of pleural symphysis and 
subsequent removal of the TIPC. ${ }^{33}$ Interestingly, there may also be a role for pleurodesis agents delivered through the TIPC if catheter drainage alone does not initially lead to spontaneous pleurodesis and the patient's clinical situation and goals warrant this additional treatment. ${ }^{41-43}$

Few studies have included analysis of the cost effectiveness of the TIPC. One recent analysis by Olden et al. found the TIPC to be slightly more expensive than talc pleurodesis $(\$ 9,012$ versus $\$ 8,171$ USD) with similar effectiveness. ${ }^{44}$ However, sensitivity analysis suggested that TIPC may be cost effective for patients with a prognosis of 6 weeks or less. Putnam et al. found that early mean hospital charges were significantly lower in patients receiving a TIPC placed in the outpatient setting as compared to those who were treated as an inpatient with either chest tube or TIPC. ${ }^{22}$ As the biggest long-term cost of the TIPC is that of the disposable vacuum drainage bottles, some of this expense could be reduced with use of alternate drainage equipment. For example, Al Halfawy and Light reported the feasibility of using a reusable plastic pump for draining pleural fluid, with a cost of only $\$ 3$ compared to $\$ 400$ per month for the disposable vacuum bottles. $^{21}$

In summary, although experience with using the TIPC for MPE is becoming more widespread, there is little existing high-quality evidence comparing the efficacy and safety of the TIPC to other available treatments. Prospective randomized studies comparing the TIPC to pleurodesis are needed before the TIPC can be definitively recommended as a firstline treatment of MPE. To best aid providers in decision making regarding the use of the TIPC, future studies should include validated measures of symptom control and quality of life, and should address characteristics of patients most likely to benefit from the TIPC.

The coal miner presented above underwent TIPC placement as a palliative option for management of his recurrent pleural effusion. The TIPC provided relief of his chest pain and shortness of breath. He continued to live at home in the care of his family, without additional hospitalizations. He required one additional outpatient visit to unclog the catheter. As was his wish, the patient was able to attend his granddaughter's college graduation, and he died 11 weeks after TIPC placement with the catheter still in place.

Acknowledgements: The authors would like to thank Gloria Won, Research and Reference Librarian at the UCSF Medical Center at Mount Zion Fishbon Library, for assistance in designing the database search strategy. Drs. Van Meter and McKee were supported in part by the PRIME program in the Department of Medicine, University of California, San Francisco.

\section{Conflicts Of Interest: None disclosed.}

Open Access: This article is distributed under the terms of the Creative Commons Attribution Noncommercial License which permits any noncommercial use, distribution, and reproduction in any medium, provided the original author(s) and source are credited.

Corresponding Author: Margaret E. M. Van Meter, MD; Division of Cancer Medicine, The University of Texas MD Anderson Cancer Center, 1515 Holcombe Blvd, Unit 10, TX 77030-4009, Houston, USA (e-mail: mevanmeter@mdanderson.org).

\section{REFERENCES}

1. Antony VB, Loddenkemper R, Astoul P, et al. Management of malignant pleural effusions. American Journal of Respiratory and Critical Care Medicine. 2000;162:1987-2001.

2. Dresler CM, Olak J, Herndon JE 2nd, et al. Phase III intergroup study of talc poudrage vs talc slurry sclerosis for malignant pleural effusion. Chest. 2005;127:909-15.

3. Rehse DH, Aye RW, Florence MG. Respiratory failure following talc pleurodesis. Am J Surg. 1999;177:437-40.

4. Davies HE, Lee YC, Davies RJ. Pleurodesis for malignant pleural effusion: talc, toxicity and where next? Thorax. 2008;63:572-4.

5. Michaud G, Barclay P, Tremblay A. Tunneled pleural catheters for palliation of malignant pleural effusions. Journal of Bronchology. 2005; 12:245-8.

6. Putnam JB Jr, Light RW, Rodriguez RM, et al. A randomized comparison of indwelling pleural catheter and doxycycline pleurodesis in the management of malignant pleural effusions. Cancer. 1999;86:1992-9.

7. Guyatt GH, Oxman AD, Vist GE, Kunz R, Falck-Ytter Y, Schunemann HJ. GRADE: an emerging consensus on rating quality evidence and strength of recommendations. BMJ. 2008;336:924-6.

8. Bertolaccini L, Zamprogna C, D'Urso A, Massaglia F. The treatment of malignant pleural effusions: the experience of a multidisciplinary thoracic endoscopy group. Tumori. 2003;89:233-6.

9. Burgers JA, Olijve A, Baas P. Chronic indwelling pleural catheter for malignant pleural effusion in 25 patients. Ned Tijdschr Geneeskd. 2006; 150:1618-23.

10. Bertolaccini L, Lyberis P, Manno E, Massaglia F. Management of malignant pleural effusion by chronic indwelling pleural catheter. Lung Cancer. 2009;64:S64.

11. Bertolaccini L, Zamprogna C, Barberis L, et al. Malignant pleural effusions: review of treatment and our experience. Rev Recent Clin Trials. 2007;2:21-5.

12. Tremblay A, Mason C, Michaud G. Use of tunnelled catheters for malignant pleural effusions in patients fit for pleurodesis. Eur Respir J. 2007;30:759-62.

13. Tremblay A, Michaud GC. Single center experience with 250 tunnelled pleural catheter insertions for malignant pleural effusion. Chest. 2005; 128:321S.

14. Tremblay A, Patel M, Michaud G, Mellor J, Grondin S. Use of indwelling pleural catheters in malignant pleural effusions secondary to mesothelioma. Chest. 2004;126:735S

15. Tremblay A, Patel M, Michaud G. Use of tunneled pleural catheters in malignant mesothelioma. J Bronchology. 2005;12:203-6.

16. Warren WH, Kalimi R, Khodadadian LM, Kim AW. Management of malignant pleural effusions using the Pleurx catheter. Ann Thorac Surg. 2008;85:1049-55.

17. Mullett TW, Bernard AC, Arnold SM, Freedman Ko. Treatment of malignant pleural effusion using indwelling drains. Annals of Surgical Oncology. 2003;10:S80.

18. Wyckoff CC, Anderson ED, Read CA. The Pleurx catheter for the management of symptomatic, recurrent malignant pleural effusions: The Georgetown experience. Chest. 2003;124:130S.

19. Diez-Porres L, Alonso-Babarro A, Iglesias-Docampo A, Diaz-Agero P. Outpatient management of malignant pleural effusion with chronic pleural catheter. Palliat Med. 2008;22:775-6.

20. Robinson RD, Fullerton DA, Albert JD, Sorensen J, Johnston MR. Use of pleural Tenckhoff catheter to palliate malignant pleural effusion. Ann Thorac Surg. 1994;57:286-8.

21. Al-Halfawy A, Light R. Safety and efficacy of using a surgivac pump for the drainage of chronic indwelling pleural catheters in malignant pleural effusions. Respirology. 2008;13:461-4.

22. Putnam JB Jr, Walsh GL, Swisher SG, et al. Outpatient management of malignant pleural effusion by a chronic indwelling pleural catheter. Ann Thorac Surg. 2000;69:369-75.

23. Murthy SC, Okereke I, Mason DP, Rice TW. A simple solution for complicated pleural effusions. J Thorac Oncol. 2006;1:697-700.

24. Schneider T, Reimer P, Storz K, et al. Recurrent pleural effusion: who benefits from a tunneled pleural catheter? Thorac Cardiovasc Surg. 2009;57:42-6.

25. Sioris T, Sihvo E, Salo J, Rasanen J, Knuuttila A. Long-term indwelling pleural catheter (PleurX) for malignant pleural effusion unsuitable for talc pleurodesis. Eur J Surg Oncol. 2009;35:546-51.

26. Tremblay A, Michaud G. Single-center experience with 250 tunnelled pleural catheter insertions for malignant pleural effusion. Chest. 2006; 129:362-8. 
27. Ohm C, Park D, Vogen M, et al. Use of an indwelling pleural catheter compared with thorascopic talc pleurodesis in the management of malignant pleural effusions. Am Surg. 2003;69:198-202.

28. van den Toorn LM, Schaap E, Surmont VF, Pouw EM, van der Rijt KC, van Klaveren RJ. Management of recurrent malignant pleural effusions with a chronic indwelling pleural catheter. Lung Cancer. 2005;50:123-7.

29. Bazerbashi S, Villaquiran J, Awan MY, Unsworth-White MJ, Rahamim J, Marchbank A. Ambulatory intercostal drainage for the management of malignant pleural effusion: a single center experience. Ann Surg Oncol. 2009;16:3482-7.

30. Musani AI, Haas AR, Seijo L, Wilby M, Sterman DH. Outpatient management of malignant pleural effusions with small-bore, tunneled pleural catheters. Respiration. 2004;71:559-66.

31. Pollak JS, Burdge CM, Rosenblatt M, Houston JP, Hwu WJ, Murren J. Treatment of malignant pleural effusions with tunneled long-term drainage catheters. J Vasc Interv Radiol. 2001;12:201-8.

32. Pien GW, Gant MJ, Washam CL, Sterman DH. Use of an implantable pleural catheter for trapped lung syndrome in patients with malignant pleural effusion. Chest. 2001;119:1641-6.

33. Warren WH, Kim AW, Liptay MJ. Identification of clinical factors predicting Pleurx catheter removal in patients treated for malignant pleural effusion. Eur J Cardiothorac Surg. 2008;33:89-94.

34. Heffner JE, Nietert PJ, Barbieri C. Pleural fluid $\mathrm{pH}$ as a predictor of survival for patients with malignant pleural effusions. Chest. 2000; 117:79-86

35. Detterbeck FC, Boffa DJ, Tanoue LT. The new lung cancer staging system. Chest. 2009;136:260-71.
36. Antunes G, Neville E, Duffy J, Ali N. BTS guidelines for the management of malignant pleural effusions. Thorax. 2003;58(Suppl 2): ii29-38

37. Tremblay A. Management of malignant pleural effusions-PleurX catheter placement. Journal of Thoracic Oncology. 2009;4:S202-3.

38. Musani AI. Treatment options for malignant pleural effusion. Curr Opin Pulm Med. 2009; 15:380-7.

39. Lombardi G, Zustovich F, Nicoletto MO, Donach M, Artioli G, Pastorelli D. Diagnosis and treatment of malignant pleural effusion: a systematic literature review and new approaches. Am J Clin Oncol 2009 Oct 23 [Epub ahead of print].

40. Stather DR, Tremblay A. Use of tunneled pleural catheters for outpatient treatment of malignant pleural effusions. Curr Opin Pulm Med. 2007;13:328-33.

41. Caglayan B, Torun E, Turan D, et al. Efficacy of iodopovidone pleurodesis and comparison of small-bore catheter versus large-bore chest tube. Ann Surg Oncol. 2008;15:2594-9.

42. Wyckoff CC, Anderson ED, Read CA, Lee RE. The use of intrapleural doxycycline via pleurx catheter in the treatment of malignant pleural effusions: Preliminary report. Chest. 2007;132:432S.

43. Porcel JM, Salud A, Nabal M, Vives M, Esquerda A, RodriguezPanadero F. Rapid pleurodesis with doxycycline through a small-bore catheter for the treatment of metastatic malignant effusions. Support Care Cancer. 2006; 14:475-8.

44. Olden AM, Holloway R. Treatment of malignant pleural effusion: PleuRx ${ }^{\circledR}$ catheter or talc pleurodesis? A cost-effectiveness analysis. J Palliat Med. 2010;13:59-65. 